\title{
Occurrence of Peach Latent Mosaic Viroid in Stone Fruits and Its Transmission with Contaminated Blades
}

A. Hadidi, National Germplasm Resources Laboratory, Agricultural Research Service, USDA, Bldg 011A, Rm. 106, Beltsville, MD 20705; L. Giunchedi, Istituto di Patalogia Vegetale, Via Filippo Re, 8, 40126 Bologna, Italy; A. M. Shamloul, National Germplasm Resources Laboratory, Agricultural Research Service, USDA, Bldg 011A, Rm. 106, Beltsville, MD 20705; C. Poggi-Pollini, Istituto di Patalogia Vegetale, Via Filippo Re, 8, 40126 Bologna, Italy; and M. A. Amer, National Germplasm Resources Laboratory, Agricultural Research Service, USDA, Bldg 011A, Rm. 106, Beltsville, MD 20705

\begin{abstract}
Hadidi, A., Giunchedi, L., Shamloul, A. M., Poggi-Pollini, C., and Amer, M. A. 1997. Occurrence of peach latent mosaic viroid in stone fruits and its transmission with contaminated blades. Plant Dis. 81:154-158.

Peach latent mosaic viroid (PLMVd) is widely distributed (approximately 55\%) in peach germplasm from Europe, Asia, North America, and South America. PLMVd, or a closely related viroid, was occasionally detected in cherry, plum, and apricot germplasm from countries in Europe or Asia. The cherry isolate of PLMVd is 337 nucleotides in length and is 91 to $92 \%$ homologous to PLMVd isolates from peach. Molecular hybridization experiments demonstrated that PLMVd is not related to the agent of peach mosaic disease. PLMVd was readily transmitted (50 to 70\%) by contaminated blades to green shoots and lignified stems of peach GF-305 plants. These results indicate that the viroid may be transmitted in orchards with contaminated pruning equipment.
\end{abstract}

Additional keywords: certification, nucleotide sequence, quarantine

Peach latent mosaic disease was described first in France in the course of graft indexing of new peach cultivars on peach GF-305 indicator $(2,3)$. The disease generally is latent in peach trees for 5 to 7 years before symptoms appear. Occasionally, mosaic, blotch, vein banding, or calico symptoms appear on infected leaves. Buds show necrosis, shoot development is delayed, and branches may become necrotic and die off. Fruit symptoms consist of several small, circular, discolored areas on the fruit skin $(1,3)$. The agent of peach latent mosaic disease has never been detected from apricot, almond, cherry, prune, and plum by graft indexing on several indicator plants and re-indexing on peach GF-305 indicator (3). Natural spread of peach latent mosaic disease in peach orchards was

Corresponding author: A. Hadidi

E-mail: ahadidi@ars-grin.gov

Mention of a trademark or proprietary name does not constitute a guarantee or warranty of the product by the USDA and does not imply its approval to the exclusion of the products that may also be suitable. This article reports the results of research only.

Accepted for publication 11 October 1996.

Publication no. D-1996-1205-04R

This article is in the public domain and not copyrightable. It may be freely reprinted with customary crediting of the source. The American Phytopathological Society, 1997. observed repeatedly in France and Italy $(1,4)$ with about $5 \%$ newly infected trees being reported per year (4). In greenhouse experiments, the disease was transmissible by the green peach aphid $(5,6)$. However, the importance of aphids in the epidemiology of the disease is not yet known (6). Peach latent mosaic disease is economically important and is caused by peach latent mosaic viroid (PLMVd) $(1,7)$. The French and Italian isolates of PLMVd have been sequenced. The French isolate is 337 nucleotides (nt) in length whereas the Italian isolate is $336 \mathrm{nt}(8,11,17)$. The isolates are $95 \%$ homologous and each contains the hammerhead structure involved in the viroid self-cleavage process.

Symptoms of peach latent mosaic disease, previously reported only from Europe, appear similar to those described for peach mosaic disease in peach, which is thought to be caused by a virus and has been reported only from the southwestern U.S. and Mexico (13). On this basis alone, investigators have suggested that the two diseases are caused by the same agent $(5,8)$. Recently, however, it has been reported that the agent of peach mosaic disease is serologically related to cherry mottle leaf virus (12).

The rapid amplification of PLMVd cDNA transcribed in vitro from extracts of infected tissue is now possible with Taq DNA polymerase and viroid-specific DNA primers in a reverse transcription-polymerase chain reaction (RT-PCR) assay
(17). We have used PCR and/or recombinant DNA technology to study the occurrence of PLMVd in stone fruit and the relationship between PLMVd and the agent of peach mosaic disease, and to determine if it is possible to transmit the viroid with contaminated blades. In this paper, we report that PLMVd is widely distributed in peach, that plum, apricot, and cherry trees are also natural hosts for the viroid or a closely related one, that the nucleotide sequence of the viroid from cherry is similar to that of PLMVd from peach, that PLMVd is not related to the agent of peach mosaic disease, and that the viroid is easily transmitted by contaminated blades.

\section{MATERIALS AND METHODS}

Source of stone fruits. All stone fruit germplasm samples assayed for PLMVd, with the exception of 64 peach and 52 apricot samples from Italy, were obtained from H. E. Waterworth, Plant Germplasm Quarantine Center, Beltsville, MD. The 116 Italian samples were obtained from B. Di Terlizzi, International Center for Advanced Mediterranean Agronomic Studies, Valenzano, Bari, Italy.

Leaves of sweet cherry, Prunus avium (L.) L. 'Bing' and 'Valera,' naturally infected with PLMVd, were obtained from D. Thompson, Center for Plant Health, Agri-Food Canada, Sidney, B.C., Canada. These tissues were the source of PLMVdcherry sequenced in this investigation. The presence of PLMVd-related sequence in the source plants was identified initially by L. J. Skrzeckowski and G.I . Mink, Washington State University, Prosser, WA, with a ${ }^{32}$ P-labeled PLMVd cRNA probe (17).

Peach mosaic diseased leaf and fruit tissues with typical mosaic symptoms were obtained from G. N. Oldfield, University of California, Department of Plant Pathology, Riverside, CA, and H. J. Larsen, Colorado State University - Orchard Mesa Research Center, Grand Junction, CO.

Nucleic acid extraction. Leaf tissue $(0.2 \mathrm{~g})$ was powdered with liquid nitrogen, then extracted in TE buffer $(10 \mathrm{mM}$ Tris$\mathrm{HCl}, 1 \mathrm{mM} \mathrm{Na} 2$ EDTA, $\mathrm{pH}$ 8.0). Clarified extract was treated with an equivalent volume of phenol/chloroform (1:1) for 15 to $20 \mathrm{~min}$, then centrifuged at 3,000 rpm for 5 min at $4^{\circ} \mathrm{C}$ in a Beckman GPR centrifuge. 
Total nucleic acids were precipitated from collected supernatants by the addition of 0.1 volume of $3 \mathrm{M}$ sodium acetate, $\mathrm{pH} 5.3$ and 2.5 volumes of absolute ethanol, and the mixture was kept at $-70^{\circ} \mathrm{C}$ for at least 2 h. Nucleic acids were centrifuged in a Sorvall RC5C centrifuge at $12,000 \mathrm{rpm}$ for 10 min at $4^{\circ} \mathrm{C}$, collected pellets were resuspended in TE buffer. The total nucleic acids were concentrated with $20 \%$ polyethylene glycol (PEG) 6,000 and $2.5 \mathrm{M} \mathrm{NaCl}$ as follows: $30 \mu \mathrm{l}$ of total nucleic acids was mixed with an equal volume of PEG-NaCl solution and $\mathrm{H}_{2} \mathrm{O}$ was added to a final volume of $100 \mu \mathrm{l}$. The mixture was incubated on ice water for $1 \mathrm{~h}$ and centrifuged at 12,000 rpm for $20 \mathrm{~min}$ (Eppendorf 5415C microcentrifuge). The pellet was washed once with $70 \%$ ethanol, dried in vacuo, and dissolved in $20 \mu$ of deionized $\mathrm{H}_{2} \mathrm{O}$.

Preparation of sap extract with GeneReleaser for RT-PCR. A small disk of leaf tissue was ground with 20 to $40 \mathrm{mg}$ of 120 grit Carborundum in $100 \mu \mathrm{l}$ of TE buffer (10 mM Tris-HCl, $1 \mathrm{mM}$ EDTA, $\mathrm{pH}$ 8.0 ), and then centrifuged at $12,000 \mathrm{rpm}$ for $5 \mathrm{~min}$ at $4^{\circ} \mathrm{C}$ in the Eppendorf microcentrifuge. A 1- $\mu$ l aliquot of clarified sap was mixed with $23 \mu \mathrm{l}$ of GeneReleaser polymeric matrix (BioVentures Inc., Murfreesboro, $\mathrm{TN})(10)$ and the mixture was covered with $50 \mu \mathrm{l}$ of mineral oil. The mixture was then microwaved in a microwave oven at high power for 4,500 wattminutes (about 6 min).

PLMVd cDNA synthesis and amplification. A 20- $\mu$ l aliquot of GeneReleaser matrix containing sample was removed immediately after microwaving and added to annealing reaction mixture containing 6 $\mu \mathrm{l}$ of $5 \times$ first-strand cDNA buffer $(250 \mathrm{mM}$ Tris- $\mathrm{HCl}, \mathrm{pH} 8.3,375 \mathrm{mM} \mathrm{KCl}$, and 15 $\mathrm{mM} \mathrm{MgCl}_{2}$ ), $3 \mu \mathrm{l}$ of $0.1 \mathrm{M}$ dithiothreitol (DTT), and $1 \mu \mathrm{g}$ of PLMVd complementary primer (5'-AAC-TGC-AGT-GCTCCG-T-3') (16) to a total volume of $30 \mu \mathrm{l}$. The mixture was heated for $5 \mathrm{~min}$ at $100^{\circ} \mathrm{C}$, chilled on ice for $2 \mathrm{~min}$, and kept at $37^{\circ} \mathrm{C}$ for $30 \mathrm{~min}$ to anneal. Nineteen microliters of reaction solution $(4 \mu \mathrm{l}$ of $5 \times$ first-strand cDNA buffer, $5 \mu$ of $0.3 \mathrm{M} 2$ mercaptoethanol, $2.5 \mu \mathrm{l}$ of $10 \mathrm{mM}$ dNTPs, $1 \mu \mathrm{l}$ of RNasin (40 units per $\mu \mathrm{l}$ ), $2.4 \mu \mathrm{l}$ of DTT, $4.1 \mu \mathrm{l}$ of deionized water, and $1 \mu \mathrm{l}$ of cloned Moloney murine leukemia virus reverse transcriptase (200 units per $\mu \mathrm{l}$ ) was mixed with annealing reaction mixture and incubated at $42^{\circ} \mathrm{C}$ for 1 to $1.5 \mathrm{~h}$.

PCR amplification reaction mixtures each contained $5 \mu \mathrm{l}$ of $10 \times$ PCR buffer ( $1 \times$ $10 \mathrm{mM}$ Tris- $\mathrm{HCl}, \mathrm{pH} 8.3,50 \mathrm{mM} \mathrm{KCl}$, and $0.001 \%$ gelatin), $3 \mu \mathrm{l}$ of $25 \mathrm{mM} \mathrm{MgCl}{ }_{2}, 1$ $\mu \mathrm{l}$ of $10 \mathrm{mM}$ dNTPs, $1 \mu \mathrm{l}$ each of $6 \mu \mathrm{M}$ complementary primer and homologous primer (5'-CCC-GAT-AGA-AAG-GCTAAG-CAC-CTC-G-3') (17), 2.5 units of Taq DNA polymerase, and sterile $\mathrm{H}_{2} \mathrm{O}$ to a volume of $45 \mu$ l. Each reaction mixture was covered with 1 drop of mineral oil and "hot started" at $85^{\circ} \mathrm{C}$ for $5 \mathrm{~min}$. Five mi- croliters of cDNA mixture was added to the PCR reaction and amplified with the following cycling parameters: denaturation at $94^{\circ} \mathrm{C}$ for $30 \mathrm{~s}$, primer annealing at $62^{\circ} \mathrm{C}$ for $30 \mathrm{~s}$, and extension at $72^{\circ} \mathrm{C}$ for $45 \mathrm{~s}$, for 30 cycles with a final extension at $72^{\circ} \mathrm{C}$ for 7 min.

Analysis of RT-PCR-amplified products. Five-microliter aliquots of PCRamplified products were analyzed on $6 \%$ polyacrylamide gel $(11 \times 14 \times 0.15 \mathrm{~cm})$, in TBE buffer ( $89 \mathrm{mM}$ Tris-HCl, $89 \mathrm{mM}$ boric acid, $2.5 \mathrm{mM} \mathrm{Na}_{2}$ EDTA, $\mathrm{pH} 8.5$ ) at 120 $\mathrm{V}$ for $2.5 \mathrm{~h}$. BioLow DNA molecular weight markers (BioVentures) were used to determine the size of RT-PCR-amplified PLMVd cDNA. Gels were stained with silver nitrate.

Cloning of RT-PCR-amplified products from PLMVd-infected peach tissue and probe preparation. PCR-amplified full-length products were cloned into a Sma1 site in PUC18 and subcloned into pGEM3Zf $(+)$ as described (15). One microgram of HindIII linearized pGEM3Zf $(+)$ vector containing PLMVd insert was added to $1 \mu \mathrm{l}$ of $10 \times$ NTP labeling mixture (10 mM ATP, 10 mM CTP, 10 mM GTP, 6.5 $\mathrm{mM}$ UTP, $3.5 \mathrm{mM}$ digoxigenin [DIG]labeled UTP, in Tris-HCl, $\mathrm{pH} 7.5$ ), $2 \mu \mathrm{l}$ of $10 \times \mathrm{mM}$ transcription buffer, $2 \mu \mathrm{l}$ of $\mathrm{T} 7$ RNA polymerase, $1 \mu \mathrm{l}$ of RNase inhibitor ( 1 unit per $\mu \mathrm{l}$ ), and the final volume was completed to $20 \mu \mathrm{l}$ with diethylene pyrocarbamate (DEPC)-treated water. The mixture was mixed gently and incubated for $15 \mathrm{~min}$ at $37^{\circ} \mathrm{C}$. Two microliters of 200 mM EDTA, 0.1 volume of $4 \mathrm{M} \mathrm{LiCl}$, and 3 volumes of ethanol were added and the

Table 1. Detection of peach latent mosaic viroid (PLMVd) from peach and other stone fruit germplasm, with reverse transcription-polymerase chain reaction (RT-PCR)

\begin{tabular}{|c|c|c|c|}
\hline $\begin{array}{l}\text { Country } \\
\text { of origin }\end{array}$ & $\begin{array}{l}\text { Stone } \\
\text { fruit }\end{array}$ & $\begin{array}{c}\text { PLMVd+ } \\
\text { / tested } \\
\text { plant }^{\mathrm{a}}\end{array}$ & $\begin{array}{c}\text { PLMVd- } \\
\text { positive } \\
\text { plants } \\
(\%)\end{array}$ \\
\hline Italy & Peach $^{\mathrm{b}}$ & $29 / 64$ & 45 \\
\hline Italy & Apricot ${ }^{b}$ & $0 / 52$ & 0 \\
\hline Italy & Peach & $7 / 13$ & 54 \\
\hline Fr.Yugoslavia & Peach & $3 / 8$ & 37 \\
\hline Romania & Peach & $5 / 8$ & 62 \\
\hline Nepal & Peach & $3 / 6$ & 50 \\
\hline Pakistan & Peach & $1 / 2$ & 50 \\
\hline Japan & Peach & $2 / 2$ & 100 \\
\hline Brazil & Peach & $2 / 7$ & 29 \\
\hline USA & Peach & $5 / 7$ & 71 \\
\hline France & Apricot & $0 / 3$ & 0 \\
\hline Nepal & Apricot & $1 / 1$ & 100 \\
\hline Japan & Apricot & $1 / 1$ & 100 \\
\hline Fr.Yugoslavia & Plum & $1 / 3$ & 33 \\
\hline Romania & Plum & $1 / 3$ & 33 \\
\hline Romania & Cherry & $1 / 2$ & 50 \\
\hline Italy & Cherry & $2 / 3$ & 66 \\
\hline
\end{tabular}

a Number of PLMVd RT-PCR positive plants/ number of tested plant.

${ }^{\mathrm{b}}$ Air-dried leaf samples were obtained directly from Italy. All other samples were obtained from quarantined stone fruit germplasm in Beltsville, MD. mixture was kept at $-70^{\circ} \mathrm{C}$ for $30 \mathrm{~min}$. The mixture was centrifuged at $14,000 \mathrm{rpm}$ for $20 \mathrm{~min}$ at $4^{\circ} \mathrm{C}$ in the Eppendorf microcentrifuge. The pellet was washed with $70 \%$ ethanol, air dried, resuspended in $100 \mu \mathrm{l}$ of DEPC-treated water containing $1 \mu \mathrm{l}$ of RNase inhibitor, incubated for $30 \mathrm{~min}$ at $37^{\circ} \mathrm{C}$, and kept at $-70^{\circ} \mathrm{C}$ until used.

Cloning and nucleotide sequence of the cherry isolate of PLMVd. Ethidium bromide-stained, RT-PCR-amplified, fulllength cDNA products from viroid-infected Bing or Valera sweet cherry leaf tissue were isolated from $5 \%$ polyacrylamide gel

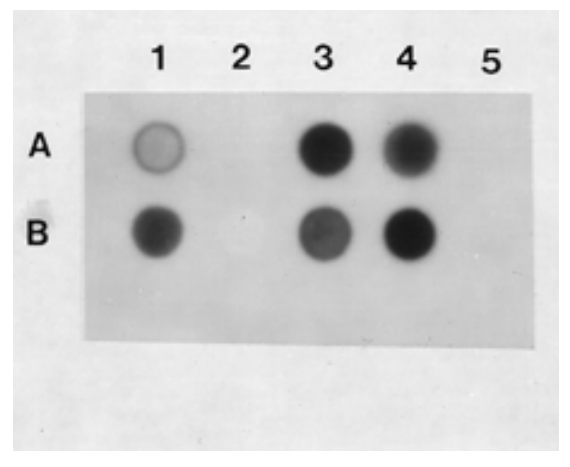

Fig. 1. Dot blot hybridization analysis of a digoxigenin (DIG)-11-labeled peach latent mosaic viroid (PLMVd) cRNA probe to total nucleic acids from leaves of stone fruits naturally infected or noninfected with PLMVd or a closely related viroid. (A) Viroid-infected plum from Romania (lane 1) and apricot from Japan and Nepal (lanes 3 and 4, respectively); noninfected plum from former Yugoslavia and apricot from France (lanes 2 and 5, respectively). (B) Viroidinfected cherry from Romania (lanes 1, 3) and peach from Italy (lane 4); noninfected cherry and peach from Italy (lanes 2 and 5, respectively).

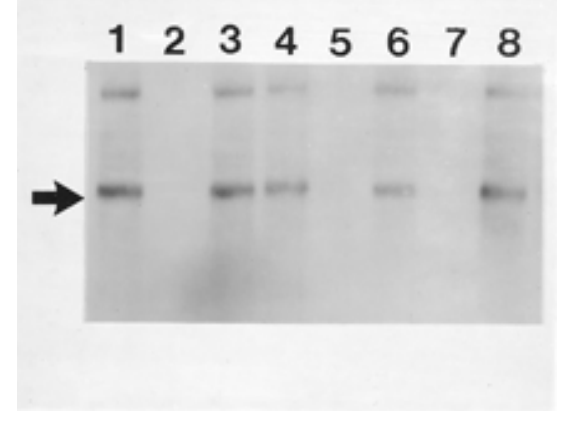

Fig. 2. Northern blot hybridization analysis of a digoxigenin (DIG)-11-labeled peach latent mosaic viroid (PLMVd) cRNA probe to total nucleic acids from leaves of stone fruits naturally infected or noninfected with PLMVd or a closely related viroid. Viroid-infected plum from Romania, apricot from Japan and Nepal, cherry from Romania, and peach from Italy (lanes $1,3,4,6$, and 8, respectively); noninfected plum from former Yugoslavia, apricot from France and cherry from Italy (lanes 2,5 and 7 , respectively). Hybridized upper bands show longer-than-unit-length and doublestranded PLMVd; hybridized lower bands show unit-length PLMVd. 
and purified by the crush and soak method (15). About $50 \mathrm{ng}$ of purified cDNA was cloned into the pCR-Script Amp SK (+) cloning vector (Stratagene Inc., La Jolla, $\mathrm{CA})$ according to the manufacturer's recommendations. cDNA inserts were sequenced by ABI-PRISM 373A Genetic Analyzer (Applied Biosystems, Foster City, CA) by the dye-primer sequencing reaction. Each nucleotide was sequenced at least once on each strand. Nucleotide sequencing was done at the University of Maryland Center for Agricultural Biotechnology, College Park.

Southern blot. Polyacrylamide gels containing separated, RT-PCR-amplified cDNA fragments were soaked twice in 0.5
$\mathrm{M} \mathrm{NaOH} / 1.0 \mathrm{M} \mathrm{NaCl}$ solution for $15 \mathrm{~min}$ each to denature DNA, neutralized twice for $15 \mathrm{~min}$ each with $0.5 \mathrm{M}$ Tris, $\mathrm{pH}$ $7.4 / 1.5 \mathrm{M} \mathrm{NaCl}$, equilibrated twice in TAE buffer $(40 \mathrm{mM}$ Tris- $\mathrm{HCl}, \mathrm{pH} 8.0,20 \mathrm{mM}$ $\mathrm{CH}_{3} \mathrm{COONa}$, and $2 \mathrm{mM} \mathrm{Na} 2 \mathrm{EDTA}$ ) for 5 min each, and then electrotransferred to TAE-equilibrated Nytran membranes (Schleicher \& Schuell, Keene, NH) at 0.6 A for $14 \mathrm{~h}$ at $4^{\circ} \mathrm{C}$. Nucleic acids were cross-linked to membranes by irradiation in a Stratagene UV cross-linker (Stratagene).

Dot blot. Ten microliters of total nucleic acids of each sample was mixed with $10 \mu \mathrm{l}$ of $20 \times \mathrm{SSC} /$ formaldehyde solution $(3: 2$ $\mathrm{vol} / \mathrm{vol}$, respectively; $1 \times \mathrm{SSC}=0.015 \mathrm{M}$ sodium citrate and $0.15 \mathrm{M} \mathrm{NaCl}, \mathrm{pH} 7.0$ ). Each mixture was kept at $65^{\circ} \mathrm{C}$ for $30 \mathrm{~min}$ and chilled on ice for $2 \mathrm{~min}$. Twenty microliters of each mixture was blotted on a wet, $0.45-\mu \mathrm{m}$ Nytran membrane (Schleicher \& Schuell) that was soaked in a $6 x$ SSC solution, then placed on a minifold apparatus under a vacuum. The membrane was washed with $200 \mu \mathrm{l}$ of $6 \times$ SSC, and then nucleic acids were cross-linked to the membrane by irradiation in a UV crosslinker.

Northern (RNA) blot. About $50 \mu$ l of total nucleic acids of each sample was mixed with $50 \mu \mathrm{l}$ of $20 \%$ PEG 6,000 and $100 \mu \mathrm{l}$ of water, then kept on ice for $1 \mathrm{~h}$. The mixture was centrifuged at $12,000 \mathrm{rpm}$
1

1

1

31

31

31

61

61

61

91

91

91

120

121

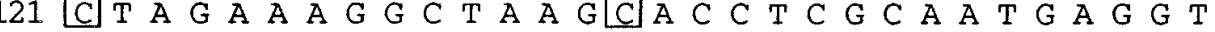

150 A A G G T G G G A C T T T T C C T T C T G G A A C C T A G C

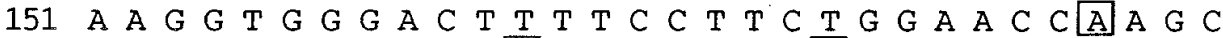

151 A A G G T G G G A C TG T T C C T T C

180 G G T A G G T T C C G A G G G G G G T G T G A T C C A G G T 181 G G T T G G T T C C G A G G G G G G T G T G A T C C A G G T 180 G G T T G G C T T C G A G G G G G G T G T G A C T C A G G T

210 A C C G C T G T A G A A A C T G G A T T A C G A C G T C T A PLMVd-cherry (Canada) 211 A C C C G C C G T A G A A A C T G G A T T A C G A C G T C T A PLMVd-peach(France) 210 A C C G C C G T A G A A A C T G A G T T A C G A C G T C T A PLMVd-peach(Italy)

240 C C A G A G A T T C A A A C C C G G T C C C C C C A G A A G PLMVd-cherry (Canada)

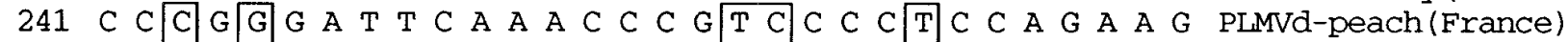
240 C C C $G$ G G G A T T C A A A C C C G T C C C C T C C A G A A G PLMVd-peach (Italy)

270 T G A T T C T G G A T G A A G A G T C T G T G C T T A G C A PLMVd-cherry(Canada) 271 T G A T T C T G G A T G A A G A G T C T G T G C T A A G C A PLMVd-peach(France) 270 T G A T T C T G G A T G A A G A G T C T G T G C T T A G C A plimVd-peach(Italy)

300 C A C T G A T G A G T C T C T G A A A T G A GA C G A A A C 301. C A C T G A C G A G T C T C T G A G A T G A G A C G A A A C 300 C A C $T$ G A $T$ G A G T C T C T G A A A T G A G A C G A A A C
330 T C T T C T G A
$\begin{array}{llllllll}331 & \mathrm{~T} & \mathrm{C} & \mathrm{T} & \mathrm{T} & \mathrm{C} & \mathrm{T} & \mathrm{T}\end{array}$
330 T C T T C TL

PLMVd-cherry (Canada) PLMVd-peach (France) PLMVd-peach (Italy)

PLMVd-cherry (Canada) PLMVd-peach (France) PLMVd-peach (Italy)

Fig. 3. The complete nucleotide sequence of cloned peach latent mosaic viroid (PLMVd) from sweet cherry cv. Bing. Nucleotide sequences of the Italian and French peach isolates of PLMVd are from published sequence data $(8,17)$. Nucleotides that differ from those of the sweet cherry isolate of PLMVd are boxed. 
for $10 \mathrm{~min}$ at $4^{\circ} \mathrm{C}$ in the Eppendorf microcentrifuge. The resulting pellet was washed with $70 \%$ ethanol, dried under vacuum, and resuspended in $10 \mu \mathrm{l}$ of TE buffer. Ten microliters of PEG-precipitated, total nucleic acids was loaded on a $6 \%$ polyacrylamide gel and electrophoresed for $1.5 \mathrm{~h}$. The gel was washed with $1 \times$ TAE for $10 \mathrm{~min}$, and total nucleic acids were electrotransferred to a TAE-equilibrated, 0.2- $\mu \mathrm{m}$ Nytran membrane at $0.5 \mathrm{~A}$ for $14 \mathrm{~h}$ at $4^{\circ} \mathrm{C}$. Nucleic acids were cross-linked to the membrane by irradiation in a UV cross-linker.

Hybridization. Membranes were prehybridized for $1 \mathrm{~h}$ at $55^{\circ} \mathrm{C}$ in prehybridization buffer $(6 \times$ SSC, $50 \%$ formamide, $1 \%$ sodium dodecyl sulfate [SDS], 10× Denhardt's reagent, and $1 \mu \mathrm{g}$ of calf thymus DNA per $\mathrm{ml}$ ), then hybridized in the same polymerase-generated PLMVd cRNA probe $(25 \mathrm{ng} / \mathrm{ml})$ or with a ${ }^{32} \mathrm{P}$-labeled PLMVd cRNA probe $\left(1 \times 10^{6} \mathrm{cpm} / \mathrm{ml}\right)$ at $55^{\circ} \mathrm{C}$ overnight in a Hybaid mini-hybridization oven (National Labnet Co., Woodbridge, NJ). Membranes were washed and exposed to X-ray film according to the manufacturer's directions (Boehringer Mannheim Corp., Indianapolis, IN)

Transmission of PLMVd with contaminated blades. Two-year-old potted GF-305 peach seedlings, grown in a greenhouse, were slash inoculated on the stem during the summer, following essentially the procedure described for inoculating citrus with the citrus exocortis viroid (9). The PLMVd source was new growth shoots 1 to $1.5 \mathrm{~cm}$ thick from field peach cv. Maria Aurella showing typical viroid discoloration spots on fruits, and another field peach cultivar, Stark Red Gold, with leaves displaying the characteristic yellow mosaic (calico) symptoms associated with some isolates of the viroid. The presence of PLMVd in the source plants was confirmed by sequential polyacrylamide gel electrophoresis analysis (16).

For inoculation, a single-edged razor blade was contaminated by drawing the blade twice slowly through one source shoot then passing it diagonally about 3 to $5 \mathrm{~mm}$ into a recipient GF-305 peach. The recipient peach was inoculated with two, four, or eight cuts in the 1-year-old lignified stem or at the base of 4-month-old buffer with a DIG-11 labeled, T7 RNA shoots. The blade was changed between plants or decontaminated by dipping in a solution of $2 \%$ sodium hypochlorite, rinsing in water, and blot-drying on absorbent paper. The inoculated cuts were wrapped with plastic budding tape. After inoculation, the plants were kept in an insect-proof screenhouse. During winter, plants were pruned and new growth was observed for disease symptoms up to September of the following year, when they were tested individually for the presence of PLMVd by the PCR technique.

Control treatments consisted of uninoculated GF-305 peach seedlings and 10 seedlings slash inoculated on the stem with a razor blade contaminated by passing four times in infected shoots, disinfected as above, and passed diagonally four to eight times in the recipient seedlings. Peach seedlings also were inoculated with bud grafts from branches with PLMVd calico symptoms on leaves.

\section{RESULTS}

Detection of PLMVd in stone fruits. RT-PCR assay was used to detect PLMVd in peach germplasm from Europe, Asia, and the Americas with an average of $55 \%$ infection (Table 1). All 52 apricot samples from Italy tested negative for PLMVd. However, apricot samples from Japan and Nepal, as well as plum and cherry samples from Romania and Italy, were PLMVd positive. Similar results were also obtained when RT-PCR products of stone fruit samples were hybridized with a DIG-11labeled PLMVd cRNA probe. To ascertain the reliability of RT-PCR/hybridization assays, especially with non-peach samples, we isolated nucleic acids from these samples and then hybridized the nucleic acids to the PLMVd cRNA probe. Dot and Northern blot hybridization analyses of total nucleic acids extracted from plum, apricot, cherry, and peach samples resulted in hybridization signals only from infected stone fruit samples (Fig. 1A and B lanes 1, 3, and 4; Fig. 2, lanes 1, 3, 4, 6, and 8). PLMVd from peach (Fig. 2, lane 8) had an electrophoretic mobility similar to the viroid from plum (Fig. 2, lane 1), apricot (Fig. 2, lanes 3 and 4), and cherry (Fig. 2, lane 6). Viroid-infected cherry, plum, and apricot plants tested positive for PLMVd with RT-PCR and different molecular hybridization assays over a 3-year period.

Nucleotide sequence of the sweet cherry isolate of PLMVd. Nucleotide sequence analysis of cloned viroids from sweet cherry plants indicated that the cherry isolate of PLMVd is $337 \mathrm{nt}$ long (Fig. 3). It differs from the 336- and 337-nt-long Italian and French peach isolates of PLMVd at 25 and 30 sites, respectively (Fig. 3). The sweet cherry isolate of PLMVd is 91 to $92 \%$ homologous to the French and Italian isolates of PLMVd from peach.

Relationship of PLMVd to the agent of peach mosaic. To determine whether or

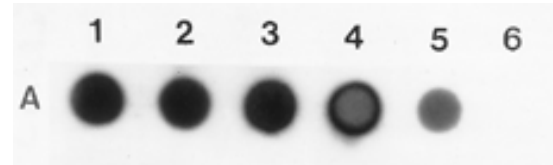

B

C

Fig. 4. Autoradiograph of dot blot hybridization analysis of a ${ }^{32} \mathrm{P}$-labeled peach latent mosaic viroid (PLMVd) CRNA probe hybridized to reverse transcription-polymerase chain reaction (RT-PCR) products amplified from nucleic acid extract of leaves from PLMVd-infected peach, peach mosaic diseased peach, apple scar skin viroid (ASSVd)-infected apple, and noninfected peach. A (lanes 1 to 5), PLMVd-infected tissue; A to C (lane 6), noninfected tissue; B (lanes 1 to 5), peach mosaic diseased tissue; $\mathrm{C}$ (lanes 1 to 5), ASSVd-infected tissue.

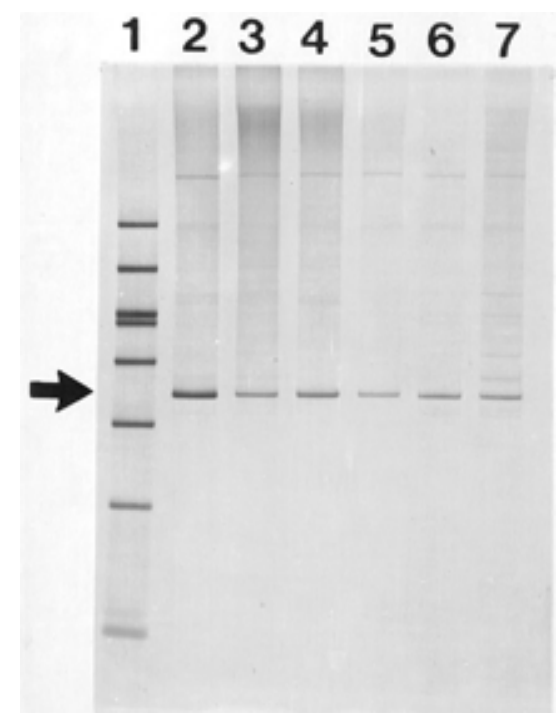
vers to peach GF-305 seedlings by contaminated razor blades

\begin{tabular}{|c|c|c|c|c|c|c|c|c|}
\hline \multirow[b]{2}{*}{ Slashed tissue } & \multicolumn{6}{|c|}{ Cuts with PLMVd-contaminated razor blades (no.) } & \multicolumn{2}{|c|}{$\begin{array}{c}\text { PLMVd- } \\
\text { transmitted }\end{array}$} \\
\hline & $2^{a}$ & $4^{a}$ & $\mathbf{8}^{\mathbf{a}}$ & $2^{\mathbf{b}}$ & $4^{b}$ & $\mathbf{8}^{\mathbf{b}}$ & $\%$ & $\%^{b}$ \\
\hline Green shoot & $6 / 10^{c}$ & $4 / 5$ & $7 / 9$ & $1 / 5$ & $3 / 4$ & $3 / 5$ & 70.8 & 50.0 \\
\hline Lignified stem $^{\mathrm{d}}$ & $6 / 8$ & $7 / 9$ & $3 / 6$ & $\mathrm{NT}^{\mathrm{e}}$ & NT & NT & 69.5 & NT \\
\hline
\end{tabular}

a Peach cv. Maria Aurella infected with a symptomless strain of PLMVd was the soruce of inoculum.

b Peach cv. Stark Red Gold infected with a PLMVd strain that produced calico symptoms on leaves was the source of inoculum.

c Number of PLMVd-positive plants/ number of slash-inoculated plants.

${ }^{\mathrm{d}}$ One year old.

e Not tested.
Fig. 5. Polyacrylamide gel electrophoretic analysis of reverse transcription-polymerase chain reaction-amplified peach latent mosaic viroid (PLMVd) cDNA from GeneReleasertreated extracts of plants slashed with viroidcontaminated blades. Lane 1, DNA marker, arrow indicates $336 \mathrm{bp}$; plants were slashed twice (lanes 2 and 3). four times (lanes 4 and 5), or eight times (lanes 6 and 7); tissues were lignified (lanes 2, 4, and 6) or green (lanes 3, 5, and 7). 
not PLMVd is related to the agent of peach mosaic, a ${ }^{32} \mathrm{P}$-labeled PLMVd cRNA probe was hybridized to RT-PCR products amplified from total nucleic acid extracts of PLMVd-infected or mosaic-diseased peach, noninfected peach, or apple scar skin viroid (ASSVd)-infected or noninfected apple (Fig. 4). Positive hybridization was only obtained with PLMVdinfected tissue (Fig 4A, lanes 1 to 5). In addition, the PLMVd cRNA probe did not hybridize to total nucleic acids from peach mosaic diseased tissue (not shown). Thus, the agent of peach mosaic disease is not an isolate of PLMVd.

Transmission of PLMVd with contaminated blades. Polyacrylamide gel electrophoretic analysis of RT-PCRamplified, PLMVd cDNA of plants slashed with the viroid-contaminated blades showed that transmission occurred (Fig. 5). Symptomless and calico isolates of PLMVd from naturally infected peach cvs. Maria Aurella and Stark Red Gold, respectively, were transmitted to peach GF305 seedlings by contaminated razor blades (Table 2). Out of 61 slashedinoculated peach plants, $40(65 \%)$ were PLMVd positive, using the RT-PCR assay. Symptomless isolate of PLMVd was transmitted efficiently with contaminated blades to both green shoots $(71 \%)$ and lignified stems (70\%) of GF-305 peach plants whereas the calico strain was transmitted less efficiently. All slash-inoculated plants, including those inoculated with the calico strain of PLMVd, failed to develop leaf symptoms. Control GF-305 plants mockinoculated with razor blades were PLMVd negative by RT-PCR assay and did not develop symptoms.

\section{DISCUSSION}

This study showed that the frequency of occurrence of natural infection by PLMVd is high in peach germplasm, that PLMVd or a closely related viroid naturally infect apricot, plum, and cherry trees, that the nucleotide sequence of the viroid from cherry is similar to that of PLMVd from peach, and that PLMVd is not related to the agent of peach mosaic disease. In addition, it demonstrated that PLMVd can be transmitted by contaminated blades. PLMVd was detected in about 55\% of peach germplasm from several countries. These results indicate that PLMVd is distributed worldwide and that peach is the major host of this viroid. PLMVd has never been detected by biological indexing from other stone fruit hosts (3). With PCR and recombinant DNA technologies, we have successfully detected PLMVd or a closely related viroid of a similar size and sequence in naturally infected apricot or plum plants. The viroid detected from sweet cherry plants is PLMVd. Nucleotide sequence analysis of cloned viroids from sweet cherry indicated that the viroid is $337 \mathrm{nt}$ long and that it is 91 to $92 \%$ ho- mologous to the French and Italian isolates of PLMVd from peach. The homology between the Italian and French isolates is 93\%. The occurrence of the viroid in plum, apricot, and cherry was rare. This could be due to strain variability or that peach cultivars are better hosts for the viroid than cultivars of the other stone fruit plant species. Detection of PLMVd or a closely related viroid in apricot or plum plants and detection of PLMVd in cherry plants will depend on the efficiency of viroid replication in cultivars of each host. Nucleotide sequence analysis of the viroid from apricot and plum species will determine its exact relationship to PLMVd.

Currently, certification and quarantine regulations in the U.S. and Canada do not require testing for PLMVd in domestic or quarantined peach, nectarine, or other stone fruits. Our investigation and that of Skrzeckowski et al. (18) suggest that consideration should be given to whether certification and quarantine regulations should be changed to prevent the introduction of PLMVd through the national and international movement of infected commercial cultivars and germplasm of stone fruits.

Symptoms of peach mosaic disease in peach (13) appear similar to those of peach latent mosaic disease. For this reason investigators suggested that the two diseases are caused by the same agent $(5,8)$. PLMVd, however, does not share any homology, as indicated by molecular hybridization experiments, to the agent of peach mosaic disease (Fig. 4). Thus, peach mosaic disease is not caused by PLMVd. Recently, it has been shown that the agent of peach mosaic reacts specifically with a monoclonal antibody made to cherry mottle leaf virus (12). These results support our findings that peach mosaic disease is not caused by PLMVd.

PLMVd was readily transmitted by contaminated blades to green shoots and lignified stems of peach GF-305 seedlings. These results suggest that the viroid may be easily transmitted in orchards from infected to healthy trees by pruning equipment. PLMVd transmission by contaminated blades to lignified stems is particularly significant since pruning is usually done on this type of wood. To our knowledge, this is the first report of transmission of PLMVd by contaminated tools. This method of transmission, however, is not uncommon for fruit tree viroids. Citrus exocortis and other citrus viroids have also been reported to be transmitted by contaminated tools $(9,14)$. Leaves of peach seedlings slash inoculated with the calico severe strain of PLMVd did not show viroid symptoms. The absence of symptoms is not surprising since severe strains of PLMVd are often unstable and revert to the symptomless condition $(3,7)$. In orchards, this condition is very common where leaves of PLMVd-infected trees with blotch or calico symptoms are present one year, then symptoms disappear the next year (L. Giunchedi, unpublished).

\section{LITERATURE CITED}

1. Albanese, G., Giunchedi, L., La Rosa, R., and Poggi-Pollini, C. 1992. Peach latent mosaic viroid in Italy. Acta Hortic. 309: 331-338

2. Desvignes, J. C. 1976 . The virus diseases detected in greenhouse and in field by the peach seedling GF305 indicator. Acta Hortic. 67:315-323

3. Desvignes, J. C. 1980. Different symptoms of peach latent mosaic. Acta Phytopathol. Acad. Sci. Hung. 15:183-190

4. Desvignes, J. C. 1981. Epidemiologie de la mosaique latente du pecher (PLMVd). Pages 263-276 in: Ler colloque sur les Recherches Fruitieres, Bordeaux.

5. Desvignes, J. C. 1986. Peach latent mosaic and its relation to peach mosaic and peach yellow mosaic virus diseases. Acta Hortic. 193:51-57

6. Flores, R., Hernandez, C., Avinent, L., Hermoso, A., Llacer, G., Juarez, J., Arregui, J. H. Nvarro, L., and Desvignes, J. C. 1992. Studies on the detection, transmission and distribution of peach latent mosaic viroid in peach trees. Acta Hortic. 309:325-330

7. Flores, R. Hernandez, C., Desvignes, J. C., and Llacer, G. 1990. Some properties of the viroid inducing peach latent mosaic disease. Res. Virol. 141:109-118

8. Hernandez, C., and Flores, R. 1992. Plus and minus RNAs of peach latent mosaic viroid self cleave in vitro via hammmerhead structures. Proc. Natl. Acad. Sci. USA 89:37113715

9. Kyriakou, A. 1992. Incidence in Cyprus of citrus exocortis viroid and its mechanical transmission. Plant Pathol. 41:20-24

10. Levy, L., Lee, I. M., and Hadidi, A. 1994. Simple and rapid preparation of infected plant tissue extracts for PCR amplification of virus, viroid, and MLO nucleic acids. J. Virol. Methods 49:295-304

11. Minafra, A., Shamloul, A. M., Hadidi, A., and Giunchedi, L. 1993. Detection and characterization of peach latent mosaic viroid by polymerase chain reaction (PCR) technology. (Abstr.) Page 319 in: Int. Congr. Plant Pathol. 6th.

12. Oldfield, G. N., Creamer, R., Gispert, C., Osorio, F., Rodriguez, R., and Perring, T. M 1995. Incidence and distribution of peach mosaic and its vector, Eriophyes insidiosus (Acari:Eriophyidae) in Mexico. Plant Dis. 79: 186-189.

13. Pine, T. S. 1976. Peach mosaic. U.S. Dept. Agric. Handb. 437:61-70

14. Roistacher, C. N., Calavan, E. C., and Blue, R. L. 1969. Citrus exocortis virus-chemica inactivation on tools, tolerance to heat and separation of isolates. Plant Dis. Rep. 53:333 336

15. Sambrook, J., Fritsch, E. F., and Maniatis, T. A. 1989. Molecular Cloning: A Laboratory Manual. 2nd ed. Cold Spring Harbor Laboratory, Cold Spring Harbor, NY.

16. Semancik, J. S., Roistacher, N. C., RiveraBustamante, R., and Duran-Vila, N. 1988. Citrus cachexia viroid, a new viroid of citrus: Relationships to viroids of the exocortis disease complex. J. Gen. Virol. 69:3059-3068

17. Shamloul, A. M., Minafra, A., Hadidi, A., Giunchedi, L., Waterworth, H. E., and Allam, E. K. 1995. Peach latent mosaic viroid: nucleotide sequencing of an Italian isolate, sensitive detection using RT-PCR and geographic distribution. Acta Hortic. 386:522-530

18. Skrzeckowski, L. J., Howell, W. E., and Mink, G. I. 1996. Occurrence of peach latent mosaic viroid in commercial peach and nectarine cultivars in the U.S. Plant Dis. 80:823. 